Revista Brasileira de Agricultura Irrigada v.14, no .4, p. 4190 - 4199, 2020

ISSN 1982-7679 (On-line)

Fortaleza, CE, INOVAGRI - http://www.inovagri.org.br

DOI: $10.7127 /$ rbai.v14n401195

Protocolo 1195.20 - 28/10/2020 Aprovado em 23/11/2020

\title{
CRESCIMENTO INICIAL DE CATINGUEIRA (Caesalpinia pyramidalis Tul) IRRIGADA COM ÁGUAS SALINAS EM DIFERENTES SUBSTRATOS
}

\author{
Geocleber Gomes de Sousa ${ }^{1}$, Krishna Ribeiro Gomes ${ }^{2}$, Maria Vanessa Pires de Souza ${ }^{3}$, Andreza de \\ Melo Mendonça ${ }^{4}$, Kelly do Nascimento Leite ${ }^{5}$, Susana Churka Blum ${ }^{6}$
}

\begin{abstract}
RESUMO
Objetivou-se com esse trabalho avaliar o efeito das águas de baixa e alta salinidade em plantas de catingueira cultivada em diferentes fertilizantes orgânicos. O trabalho foi conduzido na área experimental da Estação Agrometeorológica, UFC, em Fortaleza. O delineamento experimental empregado foi inteiramente casualizados, num esquema fatorial $3 \times 2$, referente aos fertilizantes orgânicos aplicado no substrato (biofertilizante bovino; composto orgânico e biofertilizante de caranguejo) versus dois níveis de salinidade da água de irrigação $\left(0,8\right.$ e 4,0 dS m$\left.{ }^{-1}\right)$ com 10 repetições. Aos 65 dias após o transplantio (DAT) foram analisadas as seguintes variáveis: número de folhas, altura de plantas, diâmetro do caule, área foliar, massa seca da parte aérea, massa seca da raiz, massa seca total e CEes. A irrigação com água de baixa salinidade é mais eficiente no crescimento e no acúmulo de massa seca. Os substratos com biofertilizante de caranguejo e insumo orgânico foram os que apresentaram melhores resultados para crescimento e acúmulo de massa seca.
\end{abstract}

Palavras-chave: Espécie nativa, estresse salino. adubação orgânica.

\footnotetext{
${ }^{1}$ Prof. Doutor em Engenharia Agrícola, Universidade da Integração Internacional da Lusofonia Afro-Brasileira, Av. Abolição, Redenção, CE, Brasil. E-mail: sousagg@unilab.edu.br

${ }^{2}$ Bolsista do Programa Nacional de Pós-Doutorado do Departamento de Engenharia Agrícola, Universidade Federal do Ceará, Av. Mister Hull, s/n - Pici, Fortaleza, CE, Brasil. E - mail: krishnaribeiro@yahoo.com.br

${ }^{3}$ Mestranda em Fitotecnia, Universidade Federal Rural do Semi-Árido, Rua Francisco Mota, 572 - Pres. Costa e Silva, Mossoró, RN. E-mail: vanessa.pires1993@gmail.com.br

${ }^{4}$ Mestranda em Ciências do Solo, Universidade Federal do Ceará, Av. da Universidade, 2853 - Benfica, Fortaleza, CE, Brasil. E-mail: andreza.melo2911@gmail.com

${ }^{5}$ Prof. Doutora, Universidade Federal do Acre. Rodovia BR 364, Km 04 - Distrito Industrial, Rio Branco, AC, Brasil. Email: knleite.ufac@gmail.com

${ }^{6}$ Prof. Doutora em Solos e nutrição de plantas, Universidade da Integração Internacional da Lusofonia Afro-Brasileira, Av. Abolição, Redenção, CE, Brasil. E-mail: scblum@unilab.edu.br
} 


\title{
INITIAL GROWTH OF CATINGUEIRA (Caesalpinia pyramidalis Tul) IRRIGATED WITH SALINE WATER ON DIFFERENT SUBSTRATES
}

\begin{abstract}
The objective of this work was to evaluate the effect of low and high salinity waters on catingueira plants grown on different substrates. The work was conducted in the experimental area of the Agrometeorological Station, UFC, in Fortaleza, from September to November 2013. The experimental design used was completely randomized, in a $3 \times 2$ factorial scheme, referring to organic fertilizers applied to the substrate (bovine biofertilizer; organic compound and crab biofertilizer) versus two levels of irrigation water salinity $\left(0.8\right.$ and $\left.4.0 \mathrm{dS} \mathrm{m}^{-1}\right)$ with 10 repetitions. The test was conducted in $12 \mathrm{~L}$ pots, one plant per pot. At 65 days after transplantation (DAT) the following variables were analyzed: number of leaves, plant height, stem diameter and leaf area, shoot dry mass, root dry mass, total dry mass and CEes. Irrigation with low saline water is more efficient in the growth and growth of dry matter, the substrates with crab biofertilizer and organic input were the ones that showed the best results for growth and growth of dry matter.
\end{abstract}

Keywords: Native species, salt stress, organic fertilization.

\section{INTRODUÇÃO}

A catingueira é uma espécie pertencente à família Leguminosae, possui porte arbustivo e ganhou esse nome devido as suas folhas exalarem um cheiro desagradável, é bastante encontrada na região nordeste, possuindo resistência aos déficits hídricos (ANTUNES et al., 2011). São escassos estudos com esta espécie florestal que relacionam diferentes condições de estresses ambientais, como, por exemplo, a salinidade. Contudo, alguns estudos vêm revelando estratégias em se cultivar espécies arbóreas nativas em condições de estresse salino, principalmente as de ocorrência em ecossistema de Caatinga (HOLANDA et al., 2011; GUIMARÃES et al., 2013).

A utilização de espécies com maior tolerância à salinidade tem sido outra estratégia recomendada na recuperação de solos degradados pelo excesso de sais e sódio (QADIR et al., 2007). As espécies arbóreas possuem sistema radicular profundo, podendo aumentar a permeabilidade do solo, a lixiviação dos sais e controlar o nível do lençol freático (QADIR et al., 2003).

$\mathrm{O}$ manejo inadequado da irrigação com água salina pode aumentar o teor de íons tóxicos às plantas, refletindo em alterações no potencial osmótico, na toxicidade iônica e no desequilíbrio na absorção de nutrientes (DINIZ et al., 2013). Nas plantas, a intensidade desses efeitos depende de outros fatores, tais como: espécie, cultivar, estádio fenológico da cultura, tipos dos sais, intensidade e duração do estresse salino, manejo cultural e qualidade da água de irrigação (NEVES et al., 2009; SOUSA et al., 2012a).

Sousa et al. (2012b) avaliando o crescimento de espécies arbóreas em solo salinizado, concluíram que o excesso de sódio afetou o desenvolvimento da catingueira, angico e aroeira em altura, massa seca da parte aérea e da raiz. Guimarães et al. (2013) avaliando o efeito da salinidade da água de irrigação na emergência e crescimento inicial de plântulas de mulungu, constataram que essa espécie não tolera salinidade da água acima de $0,5 \mathrm{dS} \mathrm{m}^{-1}$ sem perda da qualidade das mudas.

Objetivou-se com esse trabalho avaliar o efeito da água de baixa e alta salinidade em plantas de catingueira cultivada em diferentes fertilizantes orgânicos.

\section{MATERIAL E MÉTODOS}

$\mathrm{O}$ experimento foi conduzido em estufa telada na Estação Agrometeorológica, CCA, UFC, Campus do Pici, Fortaleza, Ceará, localizada nas coordenadas geográficas $03^{\circ} 44^{\prime} 45^{\prime \prime}$ de latitude Sul, 38³4'55” de 
longitude Oeste, a 19,5 m de altitude. Segundo a classificação de Köppen, a área do experimento está localizada numa região de clima Aw'.

O transplantio das mudas de catingueira foi feito em vasos plásticos com capacidade de 12 litros, em setembro de 2013. O delineamento experimental empregado foi inteiramente casualizado em esquema fatorial $3 \times 2$, referente aos fertilizantes orgânicos aplicado no substrato $(\mathrm{F} 1=$ biofertilizante bovino; $\mathrm{F} 2=$ composto orgânico e F3= biofertilizante de caranguejo) versus dois níveis de salinidade da água de irrigação $\left(0,8\right.$ e 4,0 dS m $\left.{ }^{-1}\right)$ com 10 repetições.

O experimento foi conduzido a pleno sol, utilizando-se vasos com capacidade para $15 \mathrm{~L}$, preenchidos com substrato composto por arisco, areia e esterco na proporção 1:1:1, respectivamente, cuja análise química segundo a metodologia de Teixeira et al. (2017), encontra-se na Tabela 1.

Tabela 1. Atributos químicos do substrato.

\begin{tabular}{|c|c|c|c|c|c|c|c|c|c|}
\hline $\mathrm{MO}$ & $\mathrm{N}$ & $\mathrm{P}$ & $\mathrm{Mg}$ & $\mathrm{K}$ & $\mathrm{Ca}$ & $\mathrm{Na}$ & \multirow{2}{*}{$\begin{array}{c}\mathrm{pH} \\
\mathrm{H}_{2} \mathrm{O} \\
\end{array}$} & \multirow{2}{*}{ PST $(\%)$} & \multirow{2}{*}{$\begin{array}{c}\text { CEes } \\
\mathrm{dS} \mathrm{m}^{-1} \\
\end{array}$} \\
\hline 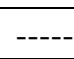 & $\begin{array}{l}---- \\
---\end{array}$ & $\mathrm{mg} \mathrm{kg}^{-1}$ & \multicolumn{4}{|c|}{ 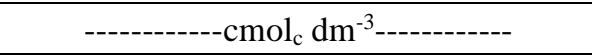 } & & & \\
\hline 3,21 & 0,18 & 54,0 & 0,90 & 0,61 & 1,50 & 0,30 & 6,0 & 9,0 & 1,1 \\
\hline
\end{tabular}

$\mathrm{Na}$ preparação da água salina foram utilizados os sais de $\mathrm{NaCl}, \mathrm{CaCl}_{2} \cdot 2 \mathrm{H}_{2} \mathrm{O}$ e $\mathrm{MgCl}_{2} \cdot 6 \mathrm{H}_{2} \mathrm{O}$, na proporção de $7: 2: 1$ (RHOADES et al., 2000). A irrigação foi iniciada após o desbaste. A irrigação foi realizada com uma frequência diária, calculada de acordo com o princípio do lisímetro de drenagem (BERNARDO et al., 2019), mantendo-se o solo na capacidade de campo.

Para o preparo do biofertilizante bovino foi utilizado $100 \mathrm{~L}$ do esterco fresco e $100 \mathrm{~L}$ de água, na proporção 1:1, deixando-se fermentar por um período de 30 dias (VIANA et al., 2013). Já para o caranguejo foi preparado a partir de uma mistura de $60 \mathrm{~kg}$ de restos de caranguejos (patas e cabeças) moídos, $5 \mathrm{~kg}$ de rapadura preta moída, 2,0 L de leite e $100 \mathrm{~L}$ de água não salina $\left(\mathrm{CEa}=0,8 \mathrm{dS} \mathrm{m}^{-1}\right)$ em um reservatório de $300 \mathrm{~L}$, deixando-se fermentar por um período de 90 dias (SOUSA et al., 2014). O composto orgânico utilizado foi adquirido de forma comercial.

Após o período de fermentação foi realizada uma análise química dos biofertilizantes cujas características encontram-se apresentadas na Tabela 2. As análises foram realizadas adotando-se as metodologias sugeridas por Malavolta et al. (1997).

Tabela 2. Composição de macronutrientes do biofertilizante bovino, caranguejo e composto orgânico.

\begin{tabular}{cccccc}
\hline & \multicolumn{5}{c}{ Características químicas } \\
\hline Fertilizantes & $\mathrm{N}$ & $\mathrm{P}$ & $\begin{array}{c}\mathrm{K} \\
\mathrm{g} \mathrm{kg}^{-1}\end{array}$ & $\mathrm{Ca}$ & $\mathrm{Mg}$ \\
\hline Biofertilizante bovino & 1,8 & 0,55 & 1,8 & 1,4 & 0,9 \\
Biofertilizante caranguejo & 0,26 & 0,26 & 4,2 & 4,0 & 0,9 \\
Composto orgânico & 2,3 & 0,87 & 3,2 & 2,5 & 2,1 \\
\hline
\end{tabular}

Aos 65 DAT, foram avaliadas as seguintes variáveis: número de folhas obtido pela contagem direta das folhas, altura de planta utilizando uma trena métrica, diâmetro do caule com o auxílio de um paquímetro digital, área foliar e a matéria seca da parte aérea, matéria seca da raiz, matéria seca total e condutividade elétrica do extrato de saturação.
Os dados após coletados foram submetidos à análise de variância (ANOVA) e a testes de médias pelo teste de Tukey aos níveis de $1 \%$ (* *) e $5 \%(*)$ de probabilidade, utilizandose 0 programa computacional ASSISTAT. 7.7 Beta (SILVA; AZEVEDO, 2016). 


\section{RESULTADOS E DISCUSSÃO}

Os maiores valores da área foliar foram verificados no tratamento com água de baixa salinidade em todos os fertilizantes (Tabela 3 ). Essa superioridade pode estar relacionada ao efeito da composição química dos substratos avaliados e da maior eficiência das plantas de catingueira nesse tipo ambiente de cultivo.

Por outro lado, o estresse salino reduziu a área foliar, promovendo menor expansão foliar, captação de $\mathrm{CO}_{2}$ e consequente mente desequilíbrio fisiológico nas plantas (PEREIRA FILHO et al., 2019).

Tabela 3. Valores médios da área foliar de plantas de catingueira cultivadas em diferentes substratos e irrigadas com água de alta e baixa salinidade.

\begin{tabular}{cccc}
\hline \multicolumn{3}{c}{ Área foliar $\left(\mathrm{cm}^{2}\right)$} \\
\hline \multirow{2}{*}{ Salinidade da água } & \multicolumn{3}{c}{ Fertilizantes } \\
\cline { 2 - 4 } & Biofertilizante Bovino & Composto orgânico & Biofertilizante de Caranguejo \\
\hline $0,8 \mathrm{dS} \mathrm{m}^{-1}$ & $184,82 \mathrm{aB}$ & $174,00 \mathrm{aB}$ & $214,40 \mathrm{aA}$ \\
$4,0 \mathrm{dS} \mathrm{m}^{-1}$ & $94,64 \mathrm{bB}$ & $81,68 \mathrm{bB}$ & $132,82 \mathrm{bA}$ \\
\hline
\end{tabular}

Médias seguidas de mesma letra, minúscula na coluna e maiúscula na linha, não diferem estatisticamente pelo teste de Tukey a $5 \%$ de probabilidade.

Resultados em que a salinidade reduziu a área foliar mesmo na presença de biofertilizantes também foram encontrados por Cavalcante et al. (2016) e Diniz et al. (2014) em mudas de oiticica. Já em estudos realizados por Melo Filho et al. (2017) na cultura da pitombeira, constataram efeito isolado para os níveis salinos da água de irrigação que reduziram a área foliar, e quando na presença de biofertilizante bovino as plantas conseguiram obter um maior desenvolvimento em área.

Em espécies agrícolas como amendoim e melão, pesquisas revelaram redução da área foliar (FERREIRA et al., 2011; SOUSA et al., 2012b).
Esses autores cultivaram essas espécies em substratos composto por classe de solo do tipo Argissolo Vermelho Amarelo mais resíduos de caranguejo e biofertilizante bovino de fermentação anaeróbia sob estresse salino e registraram similaridade ao desse estudo.

De acordo com a tabela 4, constatou-se reduções de 33,06 \% para biofertilizante de caranguejo, 23,25 \% composto orgânico e a menor redução para altura de plantas foi observada na presença do biofertilizante bovino $13,23 \%$, em relação aos tratamentos com baixa salinidade. Diniz et al. (2014) observaram efeito atenuador do biofertilizante bovino em mudas de oiticica quando irrigadas com águas de salinidade crescente.

Tabela 4. Valores médios da altura de plantas de catingueira cultivadas em diferentes substratos e irrigadas com água de alta e baixa salinidade

\begin{tabular}{cccc}
\hline & \multicolumn{3}{c}{ Altura de plantas $(\mathrm{cm})$} \\
\hline \multirow{2}{*}{ Salinidade da água } & \multicolumn{3}{c}{ Fertilizantes } \\
\cline { 2 - 4 } & Biofertilizante Bovino & Composto orgânico & Biofertilizante de Caranguejo \\
\hline $0,8 \mathrm{dS} \mathrm{m}^{-1}$ & $6,8 \mathrm{aC}$ & $8,6 \mathrm{aB}$ & $12,4 \mathrm{aA}$ \\
$4,0 \mathrm{dS} \mathrm{m}^{-1}$ & $5,9 \mathrm{bB}$ & $6,6 \mathrm{bB}$ & $8,3 \mathrm{bA}$ \\
\hline
\end{tabular}

Médias seguidas de mesma letra, minúscula na coluna e maiúscula na linha, não diferem estatisticamente pelo teste de Tukey a $5 \%$ de probabilidade.

Observa-se que os tratamentos com água de alta salinidade inibiu a altura de plantas de catingueira. Trabalhos semelhante ao desse estudo foram reportados por Guimarães et al. (2013) na espécie do mulungu. Os autores afirmam que as maiores alturas foram observadas quando as mudas foram irrigadas com água de salinidade $0,5 \mathrm{dS} \mathrm{m}^{-1}(24,43 \mathrm{~cm})$.

Já quando irrigadas com água de salinidade crescente $\left(7,5 \mathrm{dS} \mathrm{\textrm {m } ^ { - 1 } )}\right.$ as plantas 
alcançaram uma AP média de 7,5 cm. Para a cultura do tamarindo, Alves et al. (2019) encontraram reduções na altura das plantas com valores de 31,$11 ; 27,59$ e $21,58 \%$ aos 45,60 e 75 , respectivamente, nas mudas irrigadas com água de alta salinidade, quando comparadas com aquelas irrigadas com água de salinidade baixa.

Os valores médios para o número de folhas (Tabela 5) revela que não houve diferença estatística entre água da alta e baixa salinidade para o biofertilizante bovino, enquanto, para o composto orgânico e o biofertilizante caranguejo o número de folhas foi maior na água de baixa salinidade. Comportamento semelhante a este foi registrado também por Sousa et al. (2012b), ao estudarem os efeitos do aumento da salinidade em solo com biofertilizante bovino de fermentação aeróbia e anaeróbia no cultivo da cultura do amendoim.

Tabela 5. Valores médios do número de folhas de plantas de catingueira cultivadas em diferentes substratos e irrigadas com água de alta e baixa salinidade.

\begin{tabular}{cccc}
\hline & \multicolumn{3}{c}{ Número de folhas } \\
\hline \multirow{2}{*}{ Salinidade da água } & Biofertilizante Bovino & Composto orgânico & Biofertilizante de Caranguejo \\
\cline { 2 - 4 } & $17,0 \mathrm{aB}$ & $20,0 \mathrm{aA}$ & $21,0 \mathrm{aA}$ \\
$0,8 \mathrm{dS} \mathrm{m}^{-1}$ & $16,0 \mathrm{aA}$ & $18,0 \mathrm{bA}$ & $17,0 \mathrm{bA}$ \\
\hline $4,0 \mathrm{dS} \mathrm{m}^{-1}$ & & $0 \mathrm{aA}$.
\end{tabular}

Médias seguidas de mesma letra, minúscula na coluna e maiúscula na linha, não diferem estatisticamente pelo teste de Tukey a 5\% de probabilidade.

Ressalta-se que o estresse salino pode afetar o potencial osmótico da solução do solo, que afeta a disponibilidade de água para as plantas, dificultando sua absorção e ocasionando menor pressão de turgor, além do efeito particular no alongamento celular resultando em redução na emissão de novas folhas (GUIMARÃES et al., 2013).

Esses resultados estão coerentes com os apresentados por Oliveira et al. (2009) em plantas de moringa. $O$ efeito redutor da salinidade sobre o número de folhas também foi encontrado para outras nativas como oiticica (Licania rigida Benth ) e mulungu (Erythrina velutina Willd) (CAVALCANTE et al. 2016; GUIMARÃES et al., 2013).

De acordo com os resultados apresentados na Tabela 6, o estresse salino proporcionado pelo aumento da concentração de sais da água de irrigação, reduziu a matéria seca da parte aérea para os tratamentos com biofertilizante bovino e de caranguejo, porém com menos severidade para o tratamento com utilização de composto orgânico. Cavalcante et al. (2020) constataram que o composto orgânico proporcionou as condições para o maior acúmulo de massa seca da parte aérea em mudas de oiticica, sob condições de salinidade.

Tabela 6. Valores médios da matéria seca da parte aérea de plantas de catingueira cultivadas em diferentes substratos e irrigadas com água de alta e baixa salinidade.

\begin{tabular}{cccc}
\hline \multicolumn{3}{c}{ Massa seca da parte aérea $(\mathrm{g})$} \\
\hline \multirow{2}{*}{ Salinidade da água } & \multicolumn{3}{c}{ Fertilizantes } \\
\cline { 2 - 4 } & Biofertilizante Bovino & Composto orgânico & Biofertilizante de Caranguejo \\
\hline $0,8 \mathrm{dS} \mathrm{m}^{-1}$ & $1,66 \mathrm{aB}$ & $1,91 \mathrm{aB}$ & $1,10 \mathrm{aB}$ \\
$4,0 \mathrm{dS} \mathrm{m}^{-1}$ & $1,08 \mathrm{bB}$ & $1,96 \mathrm{aA}$ & $0,94 \mathrm{bB}$ \\
\hline
\end{tabular}

Médias seguidas de mesma letra, minúscula na coluna e maiúscula na linha, não diferem estatisticamente pelo teste de Tukey a 5\% de probabilidade.

Em concordância com o presente estudo, Lima et al. (2015) afirmam que o estresse salino do solo decorrente da irrigação com água de elevada condutividade elétrica, reduz expressivamente a matéria seca da parte aérea em plantas de albísza (Albizia lebbeck (L.) 
Benth.), apresentando redução de $87 \%$ para uma salinidade de 4,5 $\mathrm{dSm}^{-1}$. Já Melo filho et al (2017), contataram redução de $66,88 \% \mathrm{em}$ mudas de pitombeira (Talisia esculenta) quando irrigada com água de alta salinidade na presença de biofertilizante bovino.

A tabela 7 revela que quando irrigada com água de maior condutividade elétrica, houve uma inibição para a matéria seca da raiz nos tratamentos com biofertilizante bovino e o composto orgânico. Este comportamento pode ser ocasionado devido ao efeito da salinidade sobre o desenvolvimento radicular e ao fato das raízes ficarem em contato direto com os sais do meio (SOUSA et al., 2018).

Tabela 7. Valores médios da matéria seca da raiz e irrigadas com água de alta e baixa salinidade.

\begin{tabular}{cccc}
\hline \multicolumn{4}{c}{ Massa seca da raiz $(\mathrm{g})$} \\
\hline \multirow{2}{*}{ Salinidade da água } & \multicolumn{3}{c}{ Fertilizantes } \\
\cline { 2 - 4 } & Biofertilizante Bovino & Composto orgânico & Biofertilizante de Caranguejo \\
\hline $0,8 \mathrm{dS} \mathrm{m}^{-1}$ & $0,58 \mathrm{aA}$ & $0,54 \mathrm{aA}$ & $0,26 \mathrm{aB}$ \\
$4,0 \mathrm{dS} \mathrm{m}^{-1}$ & $0,22 \mathrm{bB}$ & $0,33 \mathrm{bA}$ & $0,22 \mathrm{aB}$ \\
\hline
\end{tabular}

Médias seguidas de mesma letra, minúscula na coluna e maiúscula na linha, não diferem estatisticamente pelo teste de Tukey a 5\% de probabilidade.

Lima et al. (2015) estudando os efeitos da salinidade sobre plântulas de albízia (Albizia lebbeck (L.) Benth.) encontraram diminuição progressiva para matéria seca da raiz à medida que os níveis de salinidade da água de irrigação aumentaram. Já Melo Filho et al. (2017) observaram redução na massa seca da raiz em plantas de pitombeira, obtendo o menor valor quando as mudas foram irrigadas com água de $5 \mathrm{dS} \mathrm{m}^{-1}$. Em um estudo realizado com mudas de tamarino, aplicação de biofertilizante e níveis de salinidade, Alves et al. (2019) também verificaram redução para esta variável, apresentando decréscimos na ordem de 51,61\% para o nível de maior salinidade $\left(6,5 \mathrm{dS} \mathrm{m}^{-1}\right)$ e uso do insumo orgânico.
De acordo com a tabela 8, o uso da água de salinidade alta, reduziu a matéria seca total para os tratamentos com o uso de biofertilizante bovino e composto orgânico, não havendo diferença estatística para o tratamento com biofertilizante de caranguejo.

Silveira et al. (2016) relatam que as plantas submetidas ao estresse salino tendem destinar suas reservas, que antes eram utilizadas para o crescimento e desenvolvimento, para aclimatar-se as condições adversas da alta concentração de sais na solução do solo, que ocasiona redução na assimilação de carbono e consequentemente menor ganho de biomassa, refletindo diretamente na redução na massa seca.

Tabela 8. Valores médios da massa seca total de plantas de catingueira cultivadas em diferentes substratos e irrigadas com água de alta e baixa salinidade

\begin{tabular}{cccc}
\hline & \multicolumn{3}{c}{ Massa seca total $(\mathrm{g})$} \\
\hline \multirow{2}{*}{ Salinidade da água } & \multicolumn{3}{c}{ Fertilizantes } \\
\cline { 2 - 4 } & Biofertilizante Bovino & Composto orgânico & Biofertilizante de Caranguejo \\
\hline $0,8 \mathrm{dS} \mathrm{m}^{-1}$ & $1,56 \mathrm{aB}$ & $2,50 \mathrm{aA}$ & $1,20 \mathrm{aB}$ \\
$4,0 \mathrm{dS} \mathrm{m}^{-1}$ & $1,36 \mathrm{bB}$ & $1,28 \mathrm{bB}$ & $1,30 \mathrm{aB}$ \\
\hline
\end{tabular}

Médias seguidas de mesma letra, minúscula na coluna e maiúscula na linha, não diferem estatisticamente pelo teste de Tukey a 5\% de probabilidade.

Estes resultados corroboram com os encontrados por Guimarães et al. (2013) que observaram redução na matéria seca de plântulas de Mulungu quando irrigados com águas de elevada salinidade. Sousa et al. (2017) e Sousa et al. (2014) trabalhando com culturas agrícolas, constataram redução linear para matéria seca total com o aumento dos níveis de salinidade da água de irrigação, tanto na presença como na ausência de biofertilizante, para a cultura do gergelim e do amendoim, respectivamente. 
A condutividade elétrica do extrato de saturação do solo CEes apresentou maiores valores quando irrigado com água de alta salinidade, esse resultado é reflexo da adição de sais pelas águas de irrigação, tendo um aumento da CEa para todos os tratamentos ao final da fase experimental quando comparado a de baixa salinidade (tabela 9).

Tabela 9. Valores médios de condutividade elétrica do extrato de saturação do substrato irrigadas com água de alta e baixa salinidade.

\begin{tabular}{cccc}
\hline & \multicolumn{3}{c}{ CEes $\left(\mathrm{dS} \mathrm{m}^{-1}\right)$} \\
\hline \multirow{2}{*}{ Salinidade da água } & \multicolumn{3}{c}{ Fertilizantes } \\
\cline { 2 - 4 } & Biofertilizante Bovino & Composto orgânico & Biofertilizante de Caranguejo \\
\hline $0,8 \mathrm{dS} \mathrm{m}^{-1}$ & $1,78 \mathrm{aB}$ & $0,87 \mathrm{aA}$ & $2,80 \mathrm{aA}$ \\
$4,0 \mathrm{dS} \mathrm{m}^{-1}$ & $3,10 \mathrm{bC}$ & $2,80 \mathrm{aA}$ & $2,90 \mathrm{bB}$ \\
\hline
\end{tabular}

Médias seguidas de mesma letra, minúscula na coluna e maiúscula na linha, não diferem estatisticamente pelo teste de Tukey a 5\% de probabilidade.

Em condições semelhantes, Souza et al. (2019) também constataram o aumento da CEes ao final do experimento. Lima Neto et al. (2018) trabalhando com salinidade nas mudas de tamarindo, constataram crescimento linear na CEes à medida que aumentava a concentração salina. Rodrigues et al. (2018) avaliando os impactos do uso da água de diferentes salinidades em um Argissolo vermelho Amarelo, encontraram valores em média 3,2 vezes maior no nível salino mais alto do que o valor encontrado no menor nível salino $1,0 \mathrm{dS} \mathrm{m}^{-1}$, além de uma elevação no caráter salino do solo em $0,2 \mathrm{dS} \mathrm{m} \mathrm{m}^{-1}$ por aumento unitário da condutividade elétrica da água de irrigação.

\section{CONCLUSÕES}

A irrigação com água de baixa salinidade é mais eficiente no crescimento e no acúmulo de massa seca em relação a irrigação com água de alta salinidade nos substratos com fertilizantes orgânicos.

O substrato com biofertilizante de caranguejo mostrou-se mais eficiente na redução dos efeitos negativos da salinidade, para as variáveis de crescimento, quando comparado aos demais, enquanto o substrato com composto orgânico, apresentou melhores resultados para massa seca da raiz e parte aérea.

\section{REFERÊNCIAS}

ALVES, L. S.; VÉRAS, M. L. M.; MELO FILHO, J. S.; SILVA IRINEU, T. H.; DIAS, T. J. Salinidade na água de irrigação e aplicação de biofertilizante bovino no crescimento e qualidade de mudas de tamarindo. Irriga, $\mathrm{v}$. 24, n. 2, p. 254-273, 2019. https://doi.org/ 10.15809/irriga.2019v24n2p254-273.

ANTUNES, C. G. C.; PELACANI, C. R.; CONDURU, R. C.; SOUZA, J. V.; SOUZA, C. L. M.; CASTRO, R. D. Germinação de sementes de Caesalpinia pyramidalis Tul. (Catingueira) submetidas a deficiência hídrica. Revista árvore, v. 35, n.5, 2011. https://doi.org/10.1590/S010067622011000600006

BERNARDO, S.; MANTOVANI, E. C.; SILVA, D. D.; SOARES, A. A. Manual de Irrigação. 9 ed. Editora UFV, 2019, 545p.

CAVALCANTE, A. C. P.; DINIZ NETO, M. A.; CAVALCANTE, L. F.; CAVALCANTE, A. G. DINIZ, B. L. M. T.; ARAÚJO, R. da C.; MESQUITA, E. F. de; ZUZA, J. F. C. Saline water and organic matter in the development and quality of Licania rigida Benth. seedlings. African Journal of Agricultural Research, Lagos, v. 11, n. 30, p. 2796-2805, 2016. https://doi.org/10.5897/AJAR2016.11061. 
CAVAlCANTE, A. C. P.; NETO, M. A. D.; CAVALCANTE, L. F.; SOUTO, A. G. LUNA.; CAVALCANTE, A. G.; DINIZ, B. L. M. T. Biomassa e clorofila de folhas em mudas de oiticica sob irrigação por salinidade de água e adição de composto orgânico. Floresta, v. 50, n. 2, pág. 1161-1170, 2020. https://doi.org/10.1590/S141543662014000100002.

DINIZ, M. A.; SILVA, I. F.; CAVALCANTE L. F.; DINIZ, B. L. M. T.; SILVA, J. C. A.; SILVA, C. E. Mudas de oiticica irrigadas com águas salinas no solo com biofertilizante bovino e potássio. Revista Brasileira de Engenharia Agrícola e Ambiental, v 18, n. 1, p. 10-18, 2014.http://dx.doi.org/10.1590/S141543662014000100002 .

DINIZ, B. L. M. T.; CAVALCANTE, L. F.; MESQUITA, F. O.; LIMA NETO, A. J.; NUNES, J. C.; DINIZ NETO, M. A. Crescimento inicial e consumo hídrico de nim submetido ao estresse salino e biofertilizante bovino. Revista Brasileira de Ciências Agrárias, v. 8, n. 3, p. 470-475, 2013. http://dx.doi.org/10.5039/agraria.v8i3a2613.

FERREIRA, F. J.; AMORIM, A. V.; ARAÚJO, F. J. F.; LACERDA, C. F.; AQUINO, M. D. Salinização do solo e desenvolvimento de meloeiro com a aplicação de resíduo de caranguejo. Revista Brasileira de Engenharia Agrícola e Ambiental, v.15, n.4, p.359-364, 2011. http://dx.doi.org/10.1590/S141543662011000400005.

GUIMARÃES, I. P.; OLIVEIRA, F. N.; VIEIRA, F. E. R.; TORRES, S. B. Efeito da salinidade da água de irrigação na emergência e crescimento inicial de plântulas de mulungu. Revista Brasileira de Ciências Agrárias, v.8, p.137-142, 2013. http://dx.doi.org/10.5039/agraria.v8i1a2360.

HOLANDA, S. J., ARAÚJO, F. S. D., GALLÃO, M. I., \& MEDEIROS FILHO, S. Impacto da salinidade no desenvolvimento e crescimento de mudas de carnaúba (Copernicia prunifera (Miller) HE Moore). Revista
Brasileira de Engenharia Agrícola e Ambiental, v. 15, n. 1, p.47-52. 2011. https://doi.org/10.1590/S14154366201100010 0007.

LIMA NETO, A. J.; CAVALCANTE, L. F.; NUNES, J. C.; LUNA SOUTO, A. G.; FRANCISCO T. C. B. Mudas de tamarindeiro irrigadas com água salina em solo sem e com biofertilizantes. Irriga, Botucatu, v. 20, n. 4, p. 730, 2018. https://doi.org/10.15809/irriga.201$5 \mathrm{v} 20 \mathrm{n} 4 \mathrm{p} 730$.

LIMA, M. F. P.; PORTO, M. A. F.; TORRES, S. B.; FREITAS, R. M. O.; NOGUEIRA, N. W.; CARVALHO, D. R. Emergência e crescimento inicial de plântulas de albízia submetidas à irrigação com água salina. Revista Brasileira de Engenharia Agrícola e Ambiental, v.19, p.3-8, 2015. https://doi.org/10.1590/18071929/agriambi.v1 9n2p106-112.

MALAVOLTA, E.; VITTI, G. C.; OLIVEIRA, S. A. Avaliação do estado nutricional de plantas: princípio e aplicações, $2^{\mathrm{a}}$ ed. Potafos, Piracicaba, 1997. 201 p.

MELO FILHO, J. S.; VÉRAS, M. L. M.; ALVES, L. S.; SILVA, T. I.; GONÇALVES, A. C. M.; DIAS, T. J. Salinidade hídrica, biofertilizante bovino e cobertura vegetal morta na produção de mudas de pitombeira (Talisia esculenta). Scientia Agraria, Curitiba, v. 18, n. 3, p. 131-14, 2017. https://doi.org/10.5380/rsa.v18i3.54307.

NEVES, A. L. R.; LACERDA, C. F.; GUIMARÃES, F. V. A.; HERNANDEZ, F. F. F.; SILVA, F. B.; PRISCO, J. T.; GHEYI, H. R. Acumulação de biomassa e extração de nutrientes por plantas de feijão-de-corda irrigadas com água salina em diferentes estádios de desenvolvimento. Revista Ciência Rural, v. 39, n. 3, p.758-765, 2009. https://doi.org/10.1590/S01038478200900500 0014.

OLIVEIRA, F. R. A.; OLIVEIRA, F. A.; GUIMARAES, P. I.; MEDEIROS, J. F.; 
OLIVEIRA, M. K. T.; FREITAS, A. V. L.; MEDEIROS, M. A. Emergência de plântulas de moringa irrigada com água de diferentes níveis de salinidade. Bioscience Journal, v. 25, n. 5, p. 66-74, 2009.

PEREIRA FILHO, J. V.; VIANA, T. V. D. A.; SOUSA, G. G. D.; CHAGAS, K. L.; AZEVEDO, B. M. D.; PEREIRA, C. Respostas fisiológicas da cultura da fava submetida a estresse salino e hídrico. Revista Brasileira de Engenharia Agricola e Ambiental, v. 23, n. 12, p. 959-965, 2019. https://doi.org/10.1590/18071929/agriambi.v23n12p959-965.

QADIR, M.; OSTER, J. D.; SCHUBERT, S.; NOBLE, A. D.; SAHRAWAT, K. L. Phytoremediation of sodic and saline-sodic soils. Advances in Agronomy, v.96, p.197247, 2007. https://doi.org/10.1016/S00652113(07)96006-X.

QADIR, M.; STEFFENS, D.; YAN, F.; SCHUBERT, S. Sodium removal from a calcareous saline-sodic soil through leaching and plant uptake during phytoremediation. Land Degradation and Development, v.14, p.301-307, 2003. https://doi.org/10.1002/ldr.558.

RHOADES, J. D.; KANDIAH, A.; MASHALI, A. M. Uso de águas salinas para produção agrícola. Campina Grande: UFPB, 2000. 117p.

RODRIGUES, V. S.; SOUSA, G. G., SARAIVA, S. E. L., CARDOSO, E. R. C.; FILHO, J. V. P.; VIANA, T. V. A. Atributos químicos do solo em área cultivada com milho sob irrigação com água salina. Revista Brasileira de Agricultura Irrigada, v. 12, n. 7, p. 31293138, 2018. https://doi.org/10.7127/RBAI.V12N7001016.

SILVA, F. A. S.; AZEVEDO, C. A. V. The Assistat Software Version 7.7 and its use in the analysis of experimental data. African Journal Agricultural Research, v. 11, n. 39, p. 3733 - 3740, 2016.
SILVEIRA, J. A. G.; SILVA, S. L. F.; SILVA, E. N.; VIÉGAS, R. A. Mecanismos biomoleculares envolvidos com a resistência ao estresse salino em plantas. In: GHEYI, H.R.; DIAS, N. S.; LARCERDA, C. F. (Eds.). Manejo da salinidade na agricultura: Estudos básicos e aplicados. Fortaleza: INCTSal, 2016. Cap. 13, p. 181-197.

SOUSA G. G.; MARINHO, A. B.; ALBUQUERUQE, A. H. P.; VIANA, T. V. A.; AZEVEDO, B. M. Crescimento inicial do milho sob diferentes concentrações de biofertilizante bovino irrigado com águas salinas. Revista Ciência Agronômica, v. 43, n. 2, p.237-245, 2012a. https://doi.org/10.1590/S18066690201200020 0005.

SOUSA, F. Q.; ARAÚJO, J. L.; SILVA, A. P.; PEREIRA, F. H. F.; SANTOS, R. V.; LIMA, G. S. Crescimento e respostas fisiológicas de espécies arbóreas em solo salinizado tratado com corretivos. Revista Brasileira de Engenharia Agrícola e Ambiental, v.16, n.2, p.173-181, 2012b. http://dx.doi.org/10.1590/S141543662012000200007.

SOUSA, G. G.; FIUSA, J. N.; LEITE, K. N.; SOARES, S. C.; SILVA, G. L. Água salina e biofertilizante de esterco bovino na cultura do gergelim. Agropecuária Técnica, v. 38, n. 3, p. 117-124. 2017. https://doi.org/10.25066/agrotec.v38i3.33694.

SOUSA, G. G., LIMA, F. A., GOMES, K. R., VIANA, T. V. A.; COSTA, F. R. B.; AZEVEDO, B. M.; MARTINS, L. F. Irrigação com água salina na cultura do amendoim em solo com biofertilizante bovino. Nativa, v. 2 n. 2, p. $\quad$ 89-94, 2014. https://doi.org/10.14583/23187670.v02n02a05

SOUSA, G. G.; RODRIGUES, V. D. S.; SOARES, S. D. C.; DAMASCENO, I. N.; FIUSA, J. N.; SARAIVA, S. E. Irrigation with saline water in soybean (Glycine max (L.) Merr.) in a soil with bovine biofertilizer. Revista Brasileira de Engenharia Agrícola e 
Ambiental, v. 22, n. 9, p. 604-609, 2018. http://dx.doi.org/10.1590/18071929/agriambi. v22n9p604-609.

SOUZA, M. V. P; SOUSA, G.G.; SALES, J. R. S.; FREIRE, M. H. C.; SILVA, G. L.; VIANA, T. V. A. Água salina e biofertilizantes de esterco bovino e caprino na salinidade do solo, crescimento e fisiologia da fava. Revista Brasileira de Ciências Agrárias, v. 14, n.3, 2019.
TEIXEIRA, P. C.; DONAGEMMA G. K.; FONTANA, A.; TEIXEIRA, W. G. Manual de métodos de análise de solo. 3 . ed. Brasília, DF: Embrapa; 2017.573 p. VIANA, T. V. A.; SANTOS, A. P.; SOUSA, G. G.; NETO, L. G. P.; AZEVEDO, B. M.; AQUINO, B. F. Trocas gasosas e teores foliares de NPK em meloeiro adubado com biofertilizantes. Revista Brasileira de Ciências Agrárias, v. 8, n. 4, p. 595601, 2013. 